\title{
Atypia and follicular lesions of undetermined significance in a nodule developed in a patient treated with carbimazole for thyrotoxic goiter
}

\author{
Christian Garbar, Mascaux Corinne \\ Department of Pathology, Institut J ean Godinot, Unicancer, France \\ Correspondence: Christian Garbar. Address: Institut Jean-Godinot - Unicancer - 1 rue du G. Koenig CS 80014,51726 \\ Reims Cedex, France. Email: christian.garbar@reims.unicancer.fr
}

Received: November 6, 2013

Accepted: January 21, $2014 \quad$ Online Published: February 8, 2014

DOI : $10.5430 /$ crcp.v1n1p1

URL: http://dx.doi.org/10.5430/crcp.v1n1p1

\begin{abstract}
We report a case of thyroid fine needle aspiration cytology (FNAC) and histological study of follicular lesion of underterminated significance or nuclear atypia of undetermined significance (FLUS/AUS) observed in a 47-years-old man presenting with Graves' disease and treated by carbimazole. Thyroid nuclear atypia associated with carbimazole is well-known. However there are rare cases described in the literature. The discussion points out the differential diagnosis of specificity of nuclear atypia in the diagnosis of thyroid malignancy. In conclusion, in Graves' disease treated with carbimazole or radioactive iode, atypical cells showing rare intranuclear grooves or rare intranuclear pseudoinclusion should be interpreted with caution.
\end{abstract}

\section{Key words}

Atypia, Thyroid, FNAC, Cytology, FLUS/AUS Carbimazole

\section{Case history}

A 47-years-old man presented with Graves' disease diagnosed 5 years previously and treated by $20 \mathrm{mg}$ carbimazole and 50 $\mu \mathrm{g}$ levothyroxine. Ultrasound examination showed a moderate increase in size of the thyroid with one small right basal nodule of $0.9 \mathrm{~cm}$. The isotopic examination showed hypo-fixation that was stable during 34 months. Fine Needle Aspiration Cytology (FNAC) was performed before surgical total thyroidectomy. Indications for surgical treatment were intolerance of medical treatment and the presence of a unique isolated nodule. The surgical total thyroidectomy was performed 8 months later. The patient was not treated by radioiodine.

\section{Material and methods}

FNAC was performed using a 25 gauge needle and classically stained by Giemsa staining on conventional smears. No immunocytochemical staining was performed.

Surgical total thyroidectomy was fixed in $4 \%$ formaldehyde solution, embedded in paraffin and cut at $4 \mu \mathrm{m}$. Diagnosis was based on H\&E-stained sections and immunological staining was performed with the Automated Slide Stainers 
BenchMark ${ }^{\circledR}$ (Ventana Medical Systems Inc-Roche - Illkirch, France), according to manufacturer's instructions. Slides were incubated with a commercial monoclonal antihuman Galectin 3 antibody (clone 9C4, Novocastra; Newcastle upon-Tyne, U.K.), Cytokeratin 19 antibody (clone RCK, Dako; Glostrup, Danemark.), HBME1 antibody (HBME-1, Dako.) and Tyroxyperoxydase antibody (MoAb47, Dako).

\section{Results}

FNAC showed monolayer cell groups presenting heterogeneous nuclei with a large variation of size ( 3 to 4 fold the normal nuclei), irregular nuclear membrane, rare intranuclear grooves and coarse dark chromatin, without nuclear overlapping. A unique nuclear pseudo-inclusion was also observed (see Figure 1). There was no colloid. Considering these few nuclear atypia, a cytological diagnosis of follicular lesion of underterminated significance or atypia of undetermined significance (FLUS/AUS) was proposed, according the 2010 Bethesda system for reporting thyroid cytopathology ${ }^{[1]}$.

Figure 1. Cytological features: heterogeneous nuclear enlargement and rare intranuclear grooves or nuclear pseudoinclusion. (Giemsa, 40x magnification)

Figure 2. Same atypia in surgical sample (Hematoxylin Eosin stain, 40x magnification)

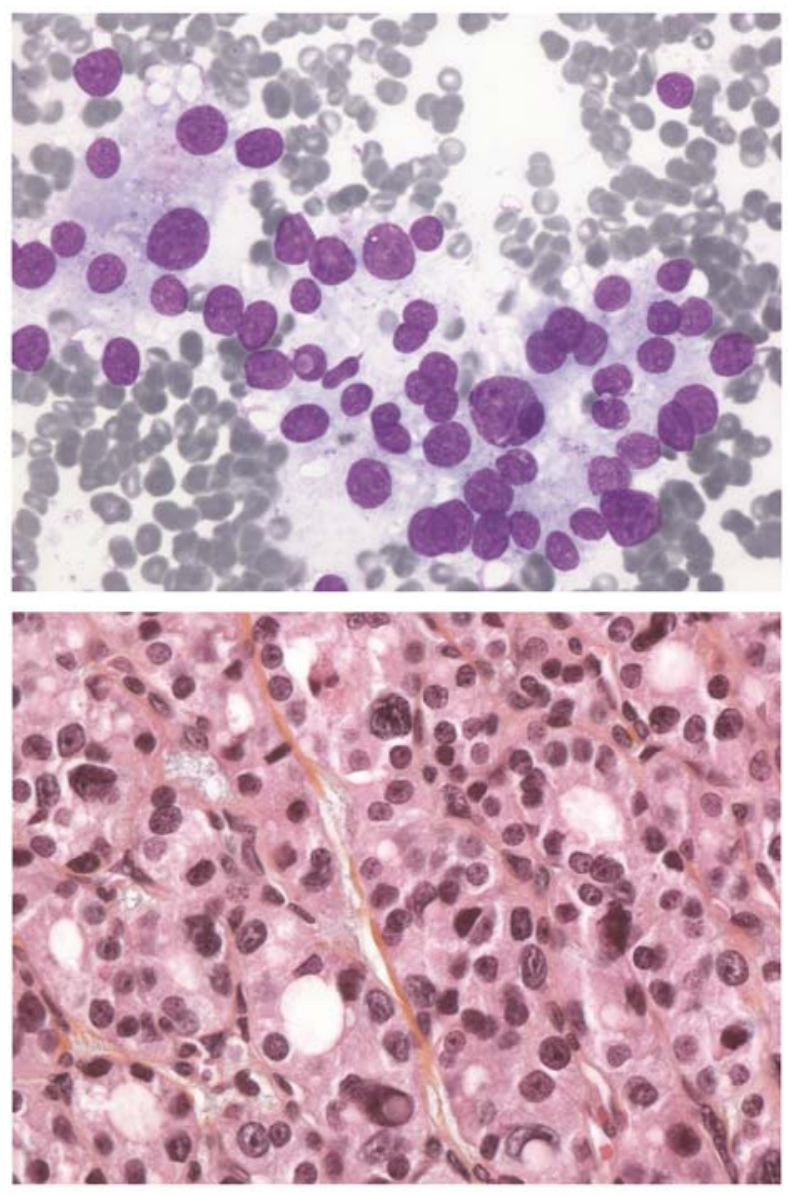

The histological slides of the surgical thyroidectomy showed obvious signs of hyperthyroidism and a small nodule of 0.9 $\mathrm{cm}$ in diameter, composed of smaller thyroid follicles with little amount of colloid. There was a fine intact capsule. The cells showed the same nuclear atypia as described in the cytological material. We noted that chromatin was coarse, not pale and not powdery. We observed nuclear polymorphism, nuclear overlapping, rare intranuclear grooves and rare nuclear pseudo-inclusion (see Figure 2) that were not enough to assert the diagnosis of malignancy. Moreover, the adjacent thyroid parenchyma also showed nuclear atypia that was however less marked. The immunohistolochemistry presented a benign phenotype: less than $5 \%$ of positive galectin 3 or cytokeratin 19 cells, negative HBME- 1 and positive TPO. A diagnosis of atypical microfollicular adenoma with nuclear atypia associated with the carbimazole treatment, was finally proposed. 


\section{Discussion}

As suggested by the Bethesda system for reporting thyroid cytopathology, we report a case of thyroid FLUS/AUS associated with the treatment of a toxic goiter ${ }^{[1,2]}$. Cibas E. et al ${ }^{[2]}$ suggested the possibility for Carbimazole inducing these reactive cellular changes. Nevertheless, the number of FLUS/AUS induced by Carbimazole was rare in the literature. The first case report concerning this cytostatic effect of Carbimazole was published by Smejkal et al., in $1985{ }^{[3]}$. Treatment with radioactive iodine gives the same nuclear changes such as chromatin clearing, rare nuclear grooves and rare nuclear pseudoinclusion suggesting papillary carcinoma ${ }^{[4]}$. A few nuclear pseudoinclusion could be also seen in other benign thyroid lesions such as benign thyroid cysts, adenomas, Hashimoto's thyroiditis and parathyroid neoplasms ${ }^{[5,6]}$. In a large series of 245 patients with Graves' disease, Kim et al. calculated a prevalence of thyroid cancer at 3.3\%. Most of them were micropapillary thyroid cancers ${ }^{[7]}$. In other words, the differential diagnosis between benign nodules and tumors developing in Graves' disease, is often difficult. Fortunately, strict cytological or histological criteria associating nuclear enlargement, nuclear overlapping, pale powdery chromatin, intranuclear grooves, and small nucleoli are enough to give a robust diagnosis of papillary tumor ${ }^{[8]}$. In our case, the atypia were suggestive for a papillary carcinoma but were insufficient to allow a diagnosis of malignancy: the atypical cells were patchy, dispersed, nuclei were more often rounded, the nuclear overlapping were not obvious and the chromatin was not pale or powdery. Only few cells showed worrying enlarged nuclei sometime associated with rare intranuclear grooves and rare nuclear pseudoinclusion. Without clinical informations, ours diagnosis of FLUS/AUS was justified and consequently the surgical thyroidectomy. Also, it's clear that the management of FLUS/AUS patients recommends a multidisciplinary approach as suggested of a lot of authors ${ }^{[9]}$. One of the solutions to reduce the uncertain diagnosis of FLUS/AUS is surely the immunocytochemistry. On a study over 150 FNAC (benign or malignant lesions or FLUS/AUS) using immunocytohemistry and liquid-based cytology, CochandPriollet et al. ${ }^{[10]}$ demonstrated an increasing of the sensitivity and specificity of cytological diagnosis. These authors recently found no false-negative immunocytochemistry in case of FLUS/AUS cytology and concluded that immunecytochemistry could be helpful in FLUS/AUS management ${ }^{[11]}$. As us, they remarked that slight atypia suggesting a papillary carcinoma were frequently applied in the FLUS/AUS category. We had already demonstrated the usefulness of liquid-based cytology to improve the immunocytochmistry, mainly by the standardisation of the cell fixation ${ }^{[12,13]}$. We are convinced that immunocytochemistry plays an important role in the routine practice of thyroid FNAC. Unfortunately, the liquid-based cytology was not available for this case. However, ours immunohistochemical study on paraffin histological sample using galectin 3, HBME1, cytokeratin 19 and TPO illustrated an benign immuno-phenotype, discarding a papillary carcinoma or other malignant follicular lesions ${ }^{[14,15]}$.

In conclusion, in Graves' disease treated with carbimazole or radioactive iodine, cells with nuclear atypia even with rare intranuclear grooves and rare pseudoinclusion, should be interpreted with caution and considered more likely as benign nodules.

\section{Conflicts of interest}

Authors disclose no potential conflict of interest.

\section{References}

[1] Syed Z.A. Thyroid Cytopathology: Bethesda and Beyond. Acta Cytol. 2011; 55: 4-12. http://dx.doi.org/10.1159/000322365

[2] Cibas S.E., Syed Z.A. The Bethesda System for Reporting Thyroid Cytopathology. Thyroid. 2009; 19: 1159-65. http://dx.doi.org/10.1089/thy.2009.0274

[3] Smejkal V, Smejkalova E, Rosa M, Zeman V, Smetana K. Cytologic changes simulating malignancy in thyrotoxic goiters treated with carbimazole. Acta Cytol. 1985; 29:173-8.

[4] Granter SR, Cibas Es. Cytologic finding in thyroid nodules after 131I treatment of hyperthyroidism. Am J Clin Pathol. 1997; 107: 20-5.

[5] Faquin W, Cibas E, Renshaw A. « Atypical » cells in fine-needle aspiration biopsy specimens of benign thyroid cysts. Cancer Cytopathol. 2005; 105: 71-9. 
[6] Goellner J, Caudill J. Intranuclear holes (cytoplasmic pseudoinclusion) in parathyroid neoplasms or "holes happen”. Cancer Cytopathol. 2000; 90: 41-6.

[7] Kim WB, Han SM, Kim TY, Nam-Goong IS, Gong G, Lee HK, et al. Ultrasonographic screening for detection of thyroid cancer in patients with Graves' disease. Clin endocrinol. 2004; 60: 719-25. http://dx.doi.org/10.1111/j.1365-2265.2004.02043.x

[8] Anderson SR, Mandel S, Livolsi VA, Gupta PK, Baloch ZW. Can morphology differentiate between benign nodules ad tumors arising in Graves' disease? Diagn Cytopathol. 2004; 31: 64-7. http://dx.doi.org/10.1002/dc.20075

[9] Dincer N, Balci S, Yazgan A, Guney G, Ersoy R, Cakir B, et al. Folow-up of atypia and follicular lesions of undetermined significance in thyroid fine needle aspiration cytology. Cytopathol. 2013; 24(6): 385-90. http://dx.doi.org/10.1111/cyt.12021

[10] Cochand-Priollet B, Dahan H, Laloi-Michelin M, Polivka M, Saada M, Herman P, et al. immunocytochemistry with cytokeratin 19 and anti-human mesothelial cell antibody (HBME1) increases the diagnostic accuracy of thyroid fine-needle aspirations: preliminary report of 150 liquid-base fine-needle aspirations with histological control. Thyroid. 2011; 21(10):1067-73. http://dx.doi.org/10.1089/thy.2011.0014

[11] Ratour J, Polivka M, Hamzi L, Kania R, Dumuis L, Cohen R, et al. Diagnosis of Follicular lesion of undeterminated significance in fine-needle aspirations of thyroid nodules. J Thyroid Res. 2013; 250347. http://dx.doi.org/10.1155/2013/250347

[12] Garbar C, Curé H. Fine-needle aspiration cytology can play a role in neoadjuvant chemotherapy in operable breast cancer. ISRN Oncol. 2013 Jul 10; 2013:935796. http://dx.doi.org/10.1155/2013/935796

[13] Garbar C, Remmelink M, Mascaux C. Fine needle aspiration cytology of lymph node: experience of 2 university hospitals with conventional smears and liquid-based cytology. Acta Cytol. 2008; 52(4): 418-23. http://dx.doi.org/10.1159/000325546

[14] Fisher S, Asa S. Apllication of immunohistochemistry to thyroid neoplasms. Arch Pathol lab Med. 2008; 132: 359-72.

[15] Luongo de Matos L, Braz del Giglio A, Ogawa Matsubayashi C, de Lima Farah M, Del Giglio A, Aparecida da Silva Pinhal M. Expression of CK-19, galectin-3 and hbme-1 in the differenciation of thyroid lesions: systematic review and diagnostic meta-analysis. Diagnostic Pathology. 2012; 7: 97. http://dx.doi.org/10.1186/1746-1596-7-97 